Supplementary Information for:

In vitro to in vivo translation of allosteric modulator concentration-effect relationships: implications for drug discovery

AUTHORS: Karen J. Gregory, Thomas M. Bridges ${ }^{\mathrm{b}}$, Rocco G. Gogliotti ${ }^{\mathrm{b}}$, Shaun R. Stauffer ${ }^{\mathrm{b}}$, Meredith J.

Noetzel $^{\mathrm{b}}$, Carrie K. Jones ${ }^{\mathrm{b}}$, Craig W. Lindsleyb,c,d, P. Jeffrey Conn ${ }^{\mathrm{b}, \mathrm{d}, \mathrm{e}}$, and Colleen M. Niswender, ${ }^{\mathrm{b}, \mathrm{d}, \mathrm{e}^{*}}$ 


\section{Supplemental Methods}

In vitro pharmacology. Rat mGlu a $_{\mathrm{a}}$ was stably expressed in Human Embryonic Kidney Cells (HEK), cultured as described in ${ }^{1}$, and assays were performed as previously described ${ }^{2}$. Rat mGlu 5 /HEK cells $(20,000$ cells/well) were plated into black-walled, clear-bottomed, tissue culture treated, 384 well plates (Greiner BioOne, Monroe, North Carolina) in DMEM containing 10\% dialyzed FBS, $20 \mathrm{mM} \mathrm{HEPES,} 100 \mathrm{U} / \mathrm{mL}$ penicillin/streptomycin, and $1 \mathrm{mM}$ sodium pyruvate (Plating Medium). The cells were grown overnight at $37^{\circ} \mathrm{C}$ in the presence of $5 \% \mathrm{CO}_{2}$. The next day, the medium was removed and replaced with $20 \mu \mathrm{L}$ of $2 \mu \mathrm{M}$ Fluo-4, AM (Invitrogen, Carlsbad, CA) prepared as a $2.3 \mathrm{mM}$ stock in DMSO and mixed in a 1:1 ratio with 10\% (w/v) pluronic acid F-127 and diluted in Assay Buffer (Hank's balanced salt solution, 20 mM HEPES and 2.5 mM probenecid (Sigma-Aldrich, St. Louis, MO)) for 45 min at $37{ }^{\circ} \mathrm{C}$. Dye was removed and replaced with $20 \mu \mathrm{L}$ of Assay Buffer and the plate was incubated for $10 \mathrm{~min}$ at room temperature. For concentration-response curve experiments, compounds were serially diluted 1:3 into 10 point concentration response curves in DMSO, transferred to daughter plates using an Echo acoustic plate reformatter (Labcyte, Sunnyvale, CA) and diluted in Assay Buffer to a $2 \mathrm{X}$ final concentration. $\mathrm{Ca}^{2+}$ flux was measured using the Functional Drug Screening System 6000 or 7000 (Hamamatsu, Japan). After establishment of a fluorescence baseline for 2 sec (2 images at $1 \mathrm{~Hz}$; excitation, $470 \pm 20 \mathrm{~nm}$; emission, $540 \pm 30 \mathrm{~nm}$ ), $20 \mu \mathrm{L}$ of test compounds were added to the cells, and the response was measured. $142 \mathrm{sec}$ later, $10 \mu \mathrm{L}(5 \mathrm{X})$ of an $\mathrm{EC}_{20}$ concentration of glutamate was added to the cells, and the response of the cells was measured. $147 \mathrm{sec}$ after this add, an $\mathrm{EC}_{80}$ concentration of glutamate was added. Calcium fluorescence was recorded as fold over basal fluorescence and raw data were normalized to the maximal response to glutamate. Potency $\left(\mathrm{EC}_{50}\right)$ and maximum response $(\% \mathrm{Glu}$ Max $)$ for compounds were determined using a four parameter logistical equation in GraphPad Prism (La Jolla, CA). For in vitro glutamate CRC fold shift experiments, multiple fixed concentrations (50 nM to $30 \mu \mathrm{M})$ of test compound or vehicle were added followed by the addition of increasing concentrations of glutamate $140 \mathrm{sec}$ later. The change in relative fluorescence over basal fluorescence was calculated before normalization to the maximal response to agonist. Shifts of agonist concentration-response curves by the modulators were globally fitted to the operational 
models of allosterism to calculate a composite $\alpha \beta$ parameter (shown below). Data (mean \pm s.e.m., $n=3$ ) were analyzed using GraphPad Prism Software (San Diego, CA).

Shifts of agonist concentration-response curves by allosteric modulators were globally fitted to an operational model of allosterism ${ }^{3}$, below:

$y=$ basal $+\frac{\left(E_{m}-\text { basal }\right)\left(\tau_{A}[A]\left(K_{B}+\alpha \beta[B]\right)+\tau_{B}[B] K_{A}\right)^{n}}{\left(\tau_{A}[A]\left(K_{B}+\alpha \beta[B]\right)+\tau_{B}[B] K_{A}\right)^{n}+\left([A] K_{B}+K_{A} K_{B}+K_{A}[B]+\alpha[A][B]\right)^{n}}$

where $A$ is the molar concentration of the orthosteric agonist; $B$ is the molar concentration of the allosteric modulator; $K_{A}$ is the equilibrium dissociation constant of the orthosteric agonist, and $K_{B}$ is the equilibrium dissociation constant of allosteric modulator. Affinity modulation is governed by the cooperativity factor $\alpha$, and efficacy modulation is described by the scaling factor $\beta$; these were solved as a composite parameter, $\alpha \beta$. The parameters $\tau_{\mathrm{A}}$ and $\tau_{\mathrm{B}}$ relate to the ability of orthosteric agonist and allosteric ligands, respectively, to directly activate the receptor. Basal, $E_{\mathrm{m}}$ and $n$ represent the basal system response, maximal possible system response, and the transducer function that links occupancy to response, respectively. For the quantification of PAM effects, the following constraints were applied: $\tau_{\mathrm{B}}$, was set to -100 as none of the compounds exhibited intrinsic agonist activity, and the $\log K_{\mathrm{A}}$ of glutamate, which was set to -6.155 based upon literature values (for rat $\left.\mathrm{mGlu}_{5}\right)^{4}$. 
Statistical Analysis. For the linear regression studies across matrices, the range of values was not constrained and the line was not forced through any specific point, such as 0 , and the slope and standard error of the fit are shown in the respective table. In each case, a single $\mathrm{X}$ value, either the $\mathrm{EC}_{50}$ or $\mathrm{EC}_{35} \%$ reversal value, was used and the y axis contained the average and s.e.m. of between 3 and 6 independent experiments. For the data in Table 5, a one-way ANOVA was performed with a Bonferroni's multiple comparison test (df, 9, 30). 

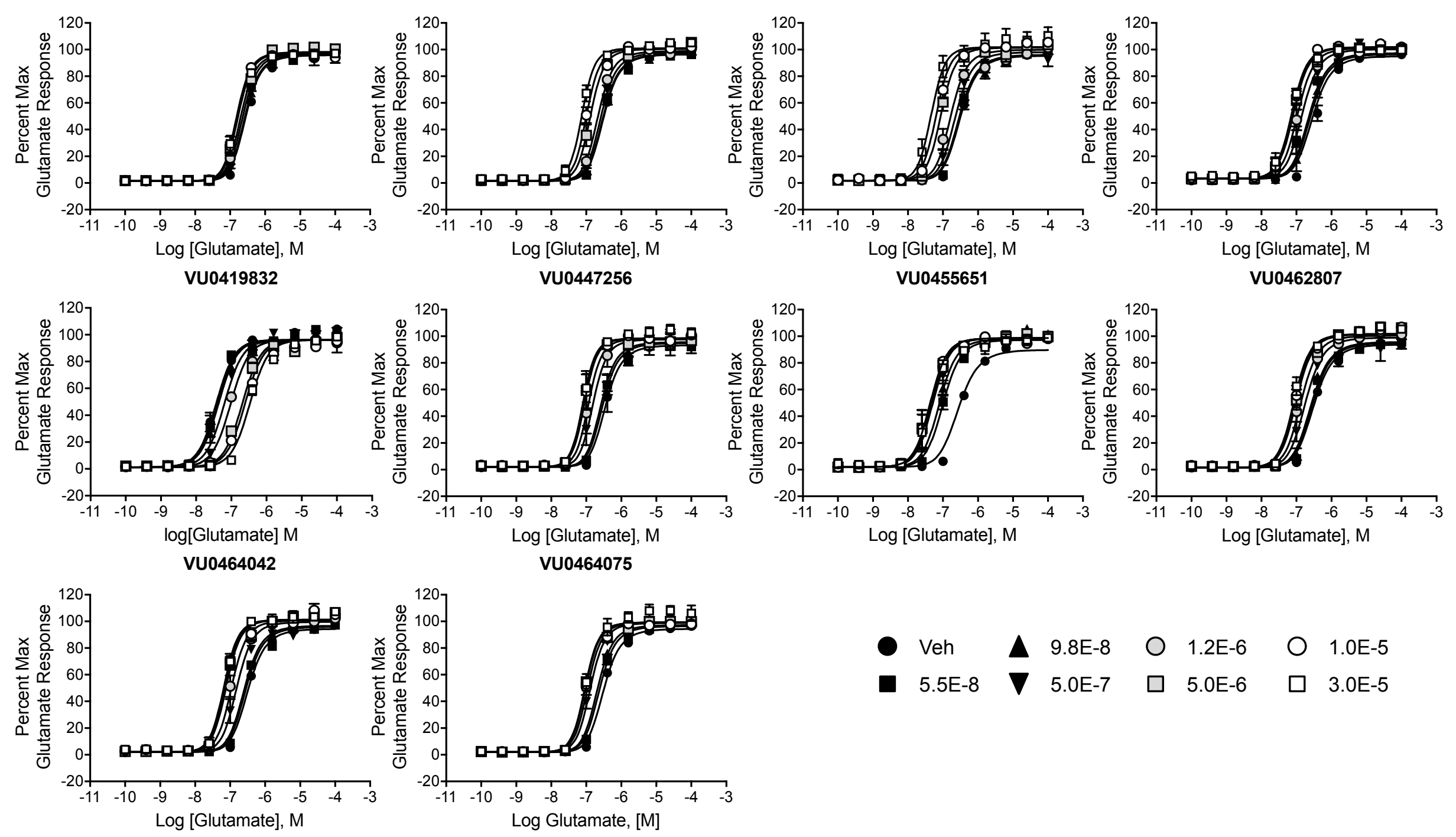

Supplemental Figure 1. Progressive fold shift determinations for the compounds depicted in Figure 1. Indicated modulator concentrations were added two minutes prior to increasing concentrations of glutamate and $\mathrm{iCa}^{2+}$ mobilization measured in $\mathrm{HEK}$ cells expressing rat mGlu $\mathrm{u}_{5 \mathrm{a}}$. Data were normalized to a maximal glutamate response $(1 \mathrm{mM})$. Data were fitted to the operational model of allosterism as described in the Materials and Methods and are mean \pm s.e.m from 3-6 independent determinations. Calculated allosteric parameters are listed for each compound in Table 1. 

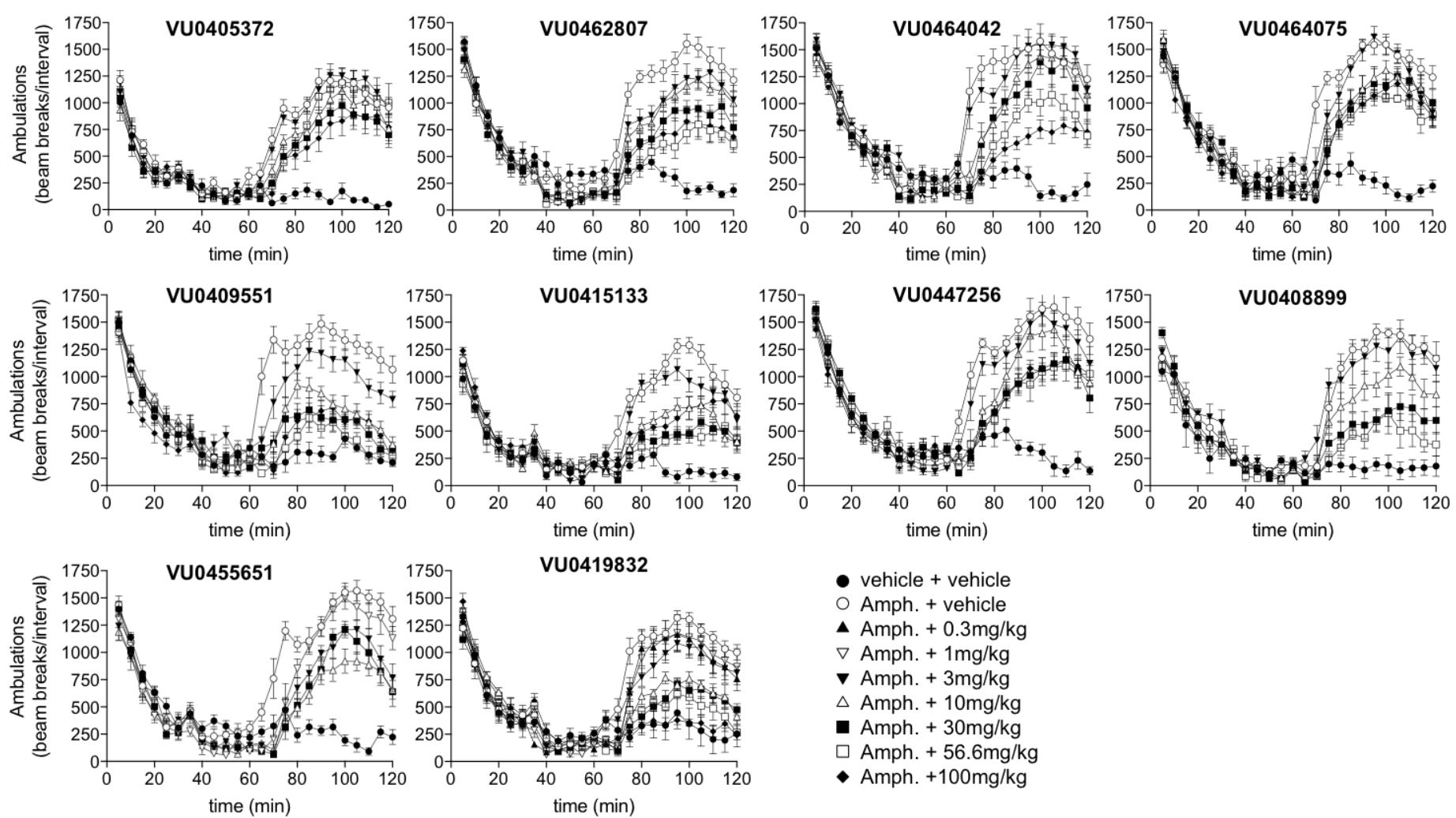

- vehicle + vehicle

○ Amph. + vehicle

$\Delta$ Amph. $+0.3 \mathrm{mg} / \mathrm{kg}$

$\nabla$ Amph. $+1 \mathrm{mg} / \mathrm{kg}$

$\boldsymbol{\nabla}$ Amph. $+3 \mathrm{mg} / \mathrm{kg}$

$\triangle$ Amph. $+10 \mathrm{mg} / \mathrm{kg}$

- Amph. $+30 \mathrm{mg} / \mathrm{kg}$

$\square$ Amph. $+56.6 \mathrm{mg} / \mathrm{kg}$

- Amph. $+100 \mathrm{mg} / \mathrm{kg}$

Supplemental Figure 2. Time course for amphetamine-induced hyperlocomotion assay. Rats were dosed with indicated dose of PAM or vehicle at $30 \mathrm{~min}$, followed by amphetamine or vehicle at $60 \mathrm{~min}$. Data are mean \pm s.e.m of beam breaks per 5 min interval from $n=5-13$ rats. As these were historical data collected over the course of the program, not all doses were administered for each compound cohort of rats. 

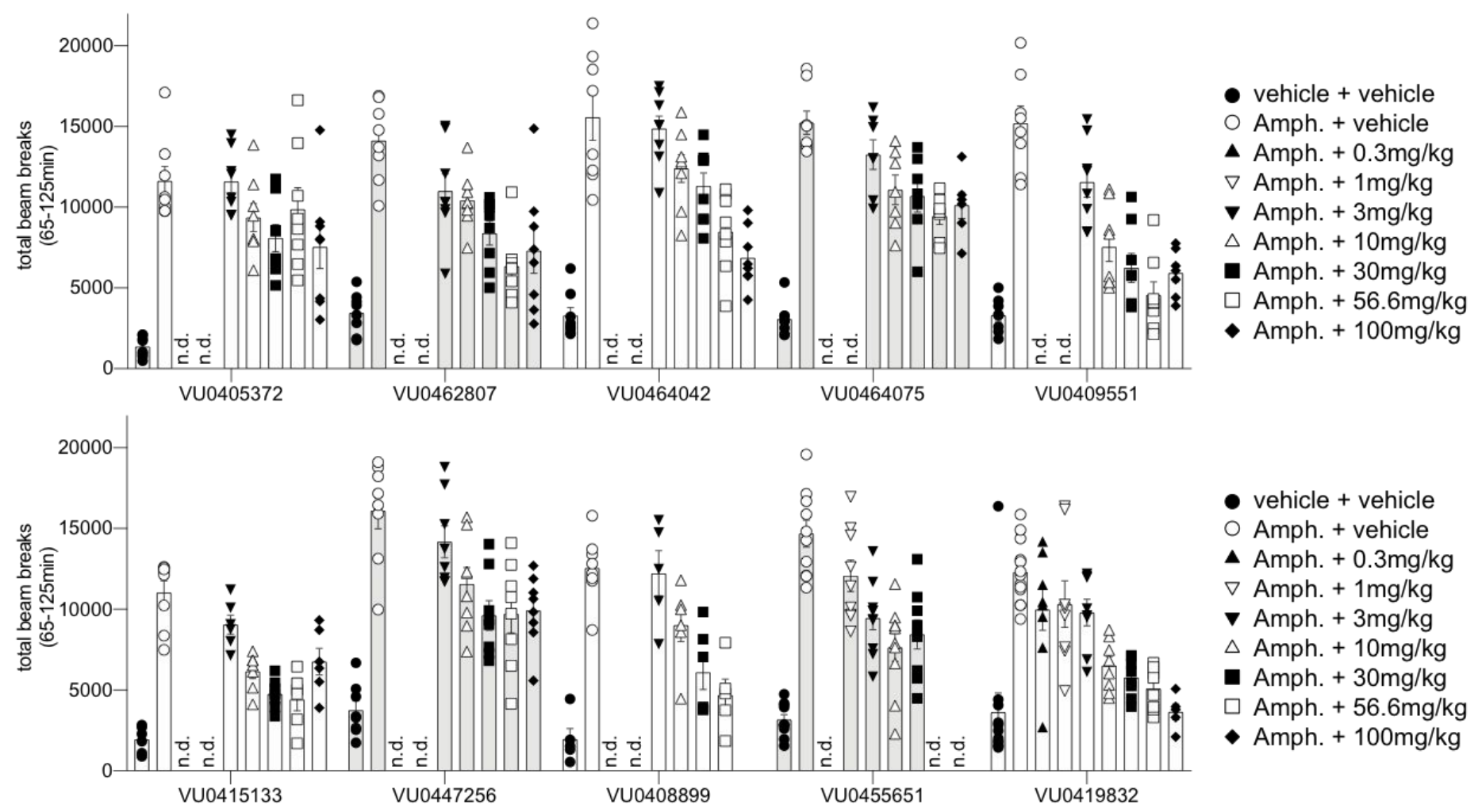

Supplemental Figure 3. Total beam breaks for each individual rat between 65-120min. Total beam breaks were used to calculate \% AHL reversal (plotted in Figure 3 and Supplemental Figure 5), where vehicle treated animals defined the maximal possible reversal (100\%) relative to the vehicle+amphetamine treated group (0\%). Each compound and associated controls were run as independent cohorts, such that every data point represents the response of an individual rat. To assist in differentiation between different treatment groups, the data sets for VU0462807, VU0464075, VU0447256 and VU0455651 have been shaded in grey. As these were historical data collected over the course of the program, not all doses were administered for each compound cohort as indicated by n.d. 

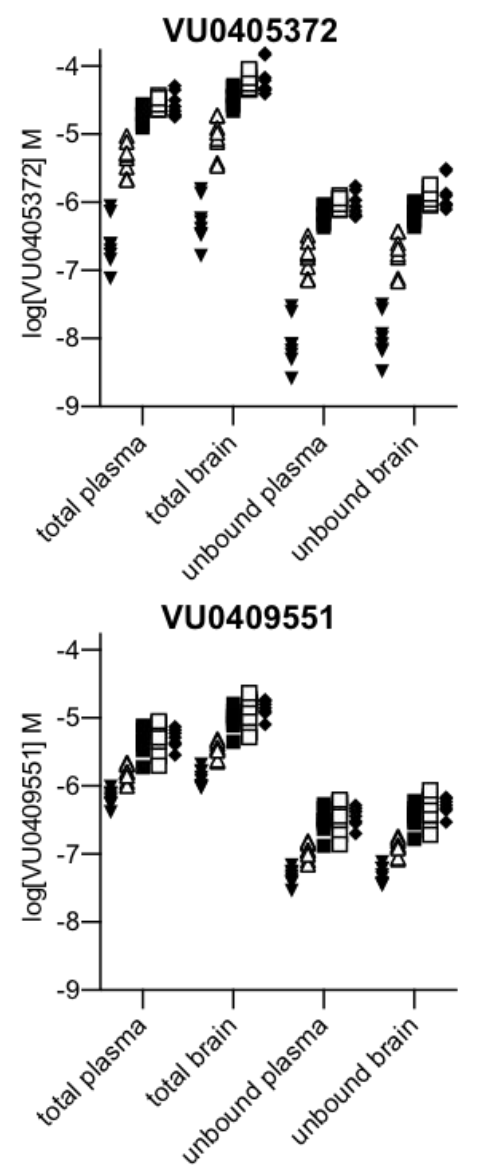

VU0455651

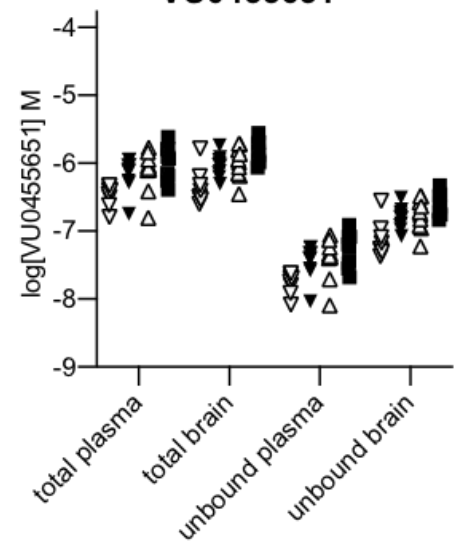

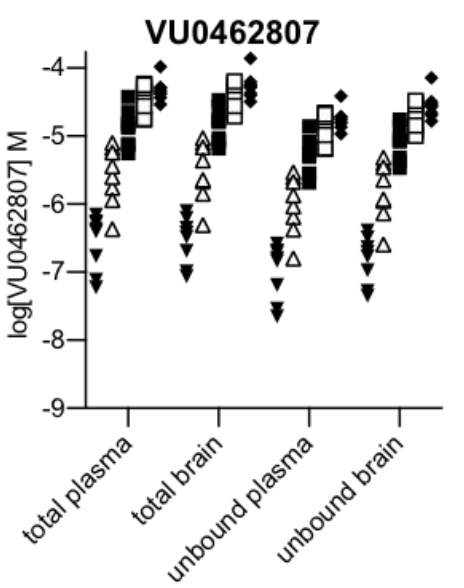
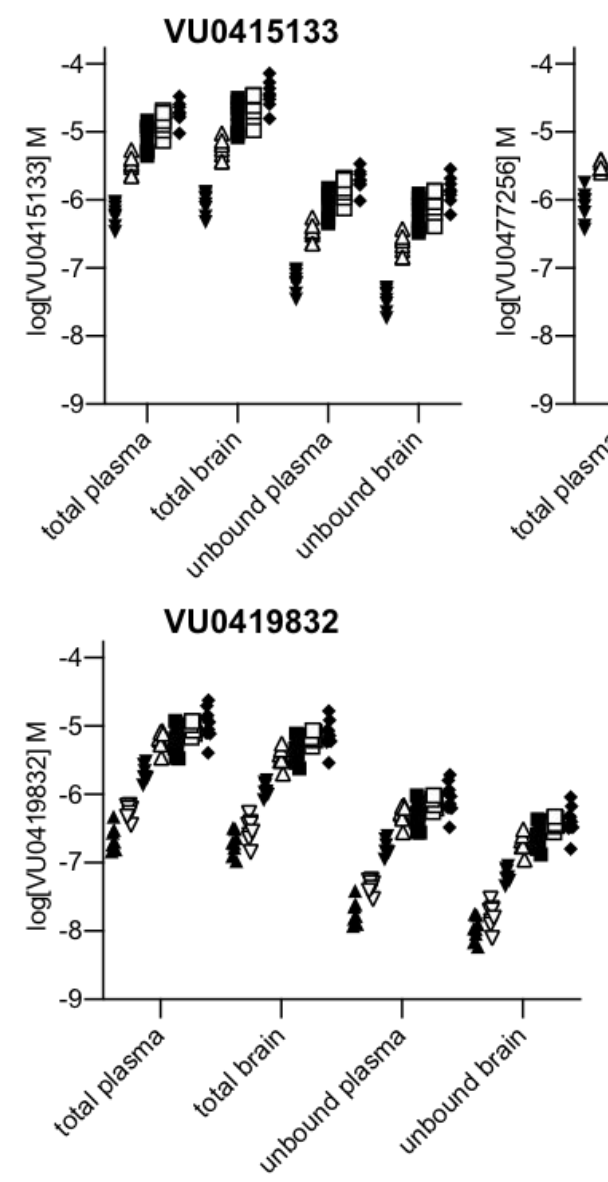

VU0464075

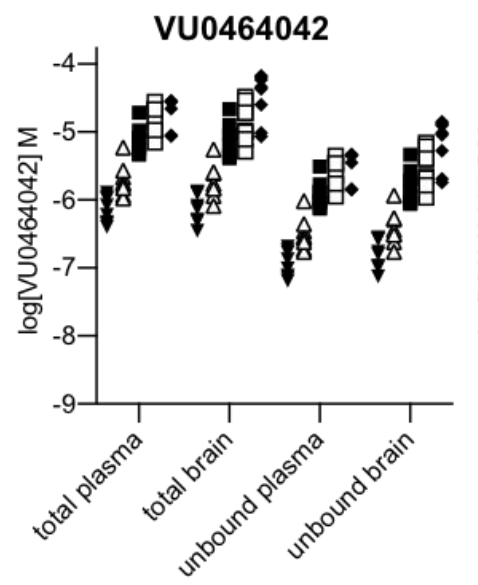

VU0447256
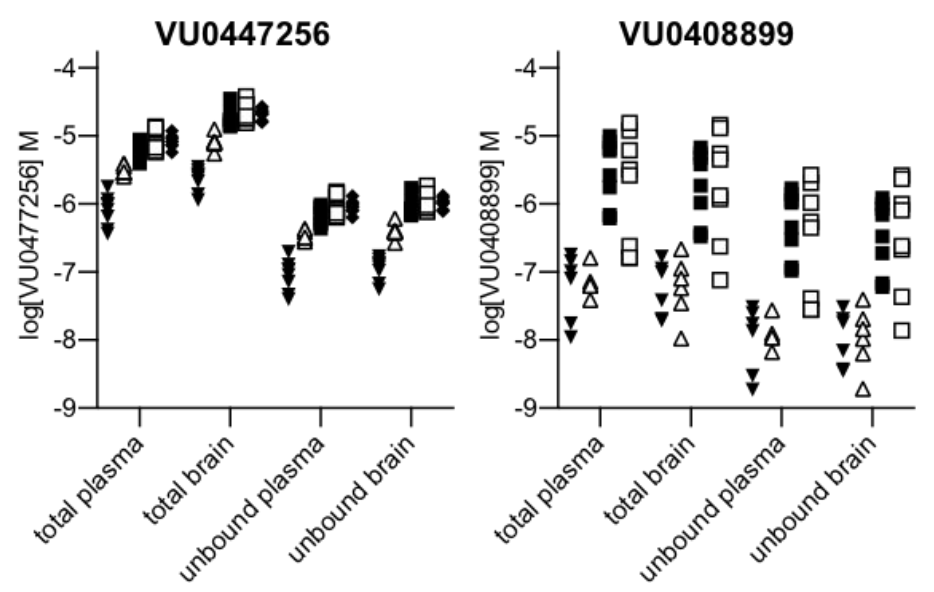

Supplemental Figure 4. Concentration of each PAM in four different matrices following indicated doses. At the end of AHL experiments, brain and plasma samples were taken and concentrations of each compound were determined via mass spectrometry relative to a standard curve of each compound. Plasma protein binding and brain homogenate binding were performed for each compound to calculate the unbound fraction in each compartment. The mean \pm s.e.m of the $\log$ concentrations were determined for generation of in vivo AHL \% reversal cncentration-response curves in Figure 3 and Supplemental Figure 5. 

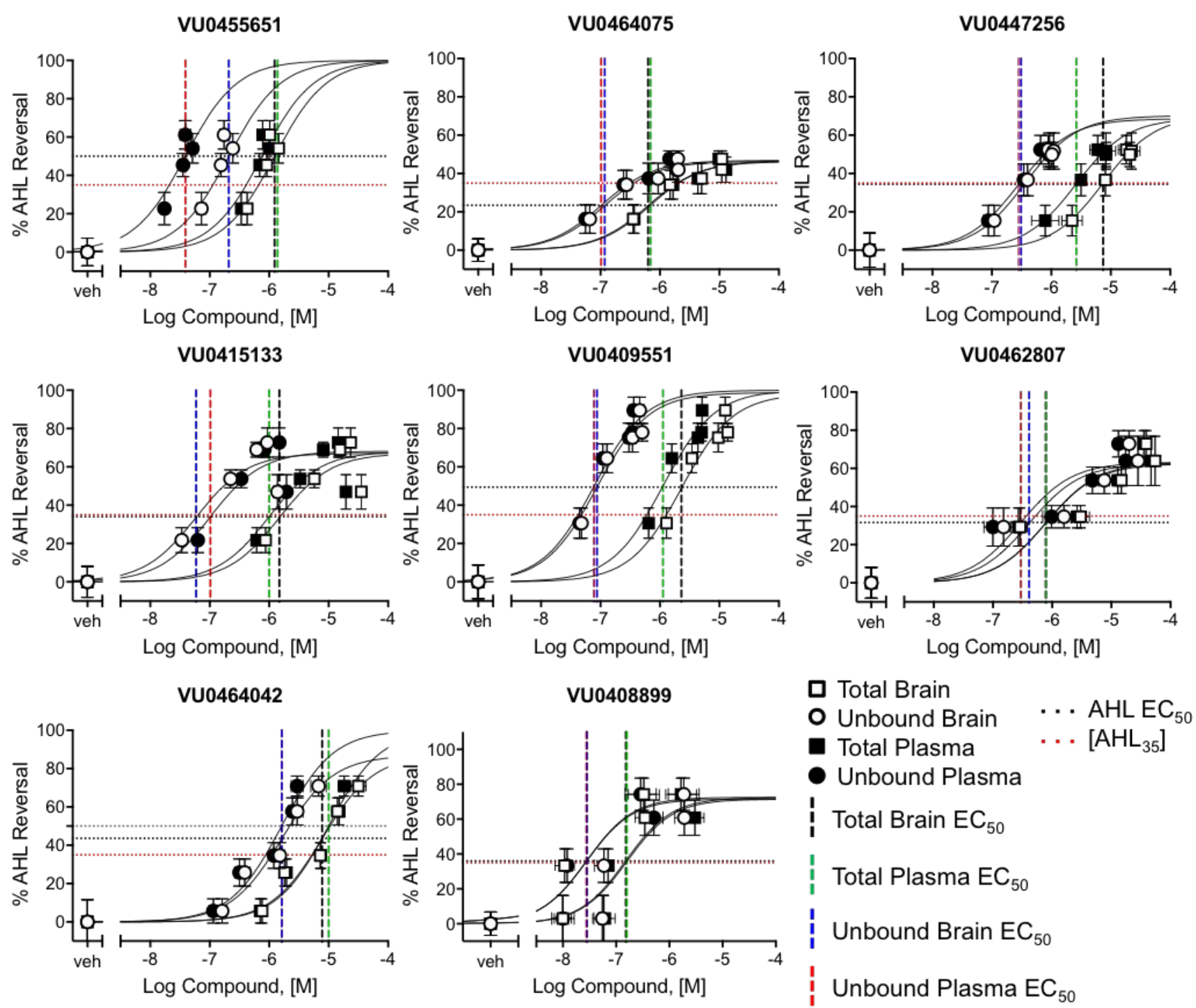

Supplemental Figure 5. Concentration-response relationships for each mGlu 5 PAM to reverse AHL based on total and unbound plasma and brain samples. AHL experiments were performed and \% reversal was calculated from total beam breaks during amphetamine exposure, where amphetamine+vehicle animals defined 0\% reversal and vehicle+vehicle was used to define 100\% reversal (Supplemental Figure 3). The mean \pm s.e.m of $\log [\mathrm{PAM}]$ for each biophase (Supplemental Figure 4) was plotted versus the \pm s.e.m. \% AHL reversal and data were fitted using a three-parameter logistical equation as described in Materials and Methods. $\mathrm{EC}_{50}$ values (horizontal black dotted line) in each of the four matrices (total brain, black vertical dashed line, unbound brain, blue vertical dashed line, total plasma, green vertical dashed line, and unbound plasma, red vertical dashed line) are shown and listed in Table 2 and Supplemental Tables 1-3. Note for VU0464042 that the span for plasma versus brain samples were different, the horizontal grey dotted line is the $\mathrm{EC}_{50}$ for plasma measurements. The concentration that reversed AHL by $35 \%$ was also derived: $\left[\mathrm{AHL}_{35}\right]$, and is shown by the horizontal dotted red line 

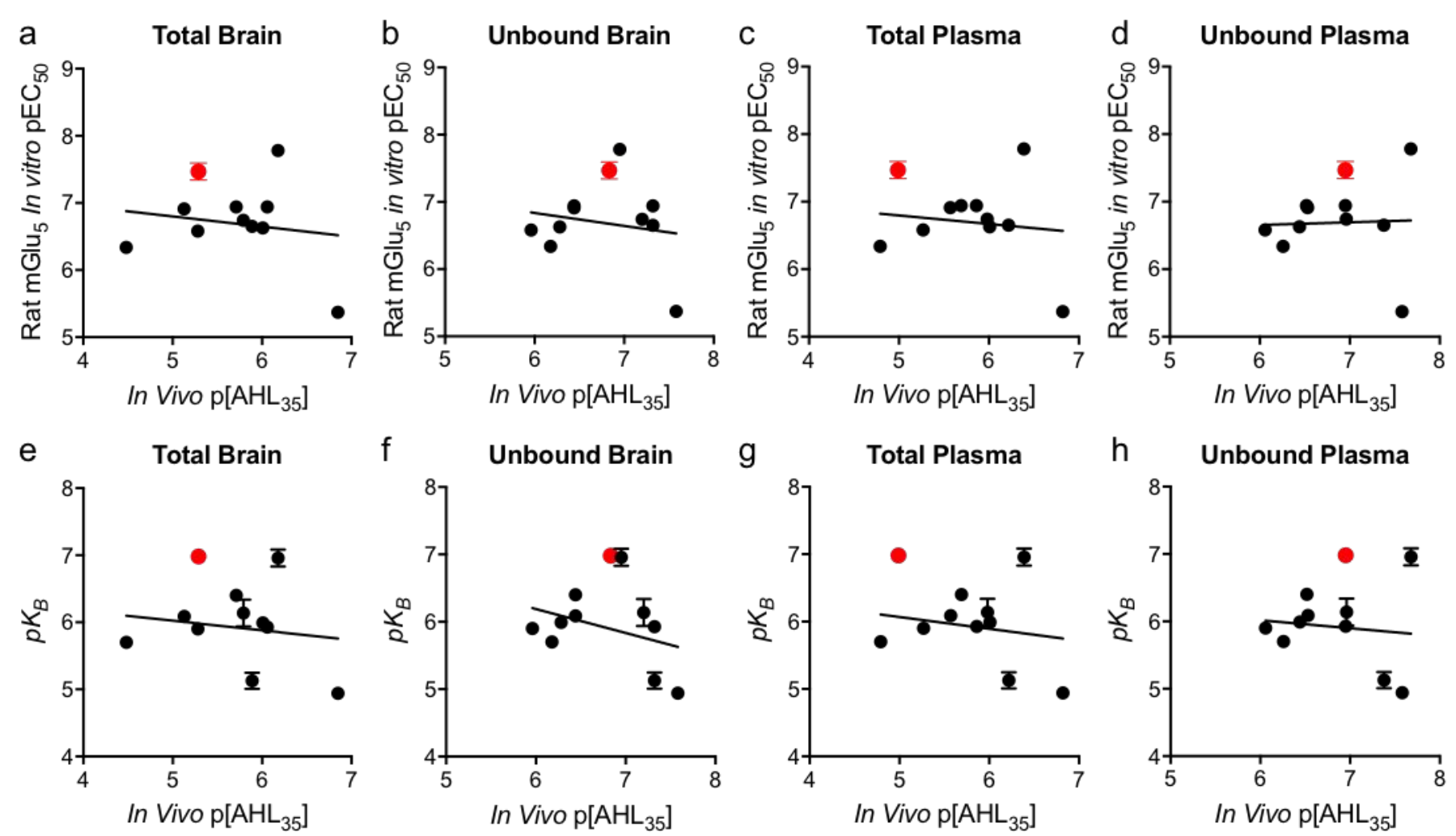

Supplemental Figure 6. In vitro potency $\left(\mathrm{pEC}_{50}\right)$ and affinity $\left(\mathrm{p} K_{B}\right)$ values do not correlate with the PAM concentration needed to induce a 35\% reversal of $\mathrm{AHL}$ p $\left[\mathrm{AHL}_{35}\right]$ regardless of matrix. Correlations for total brain (a, e), unbound brain $(\mathbf{b}, \mathbf{f})$, total plasma $(\mathbf{c}, \mathbf{g})$, and unbound plasma $(\mathbf{d}, \mathbf{h}) . \mathrm{R}^{2}$ and $\mathrm{p}$ values are listed in Table 3, excluding data for VU0360172 in red. For VU0360172, $\mathrm{pEC}_{50}$ and $\mathrm{pK}_{\mathrm{B}}$ values were taken from ${ }^{5}$ and data for AHL reversal (at $10 \mathrm{mg} / \mathrm{kg}$ i.p.) calculated from ${ }^{1}$. 
VU0455651
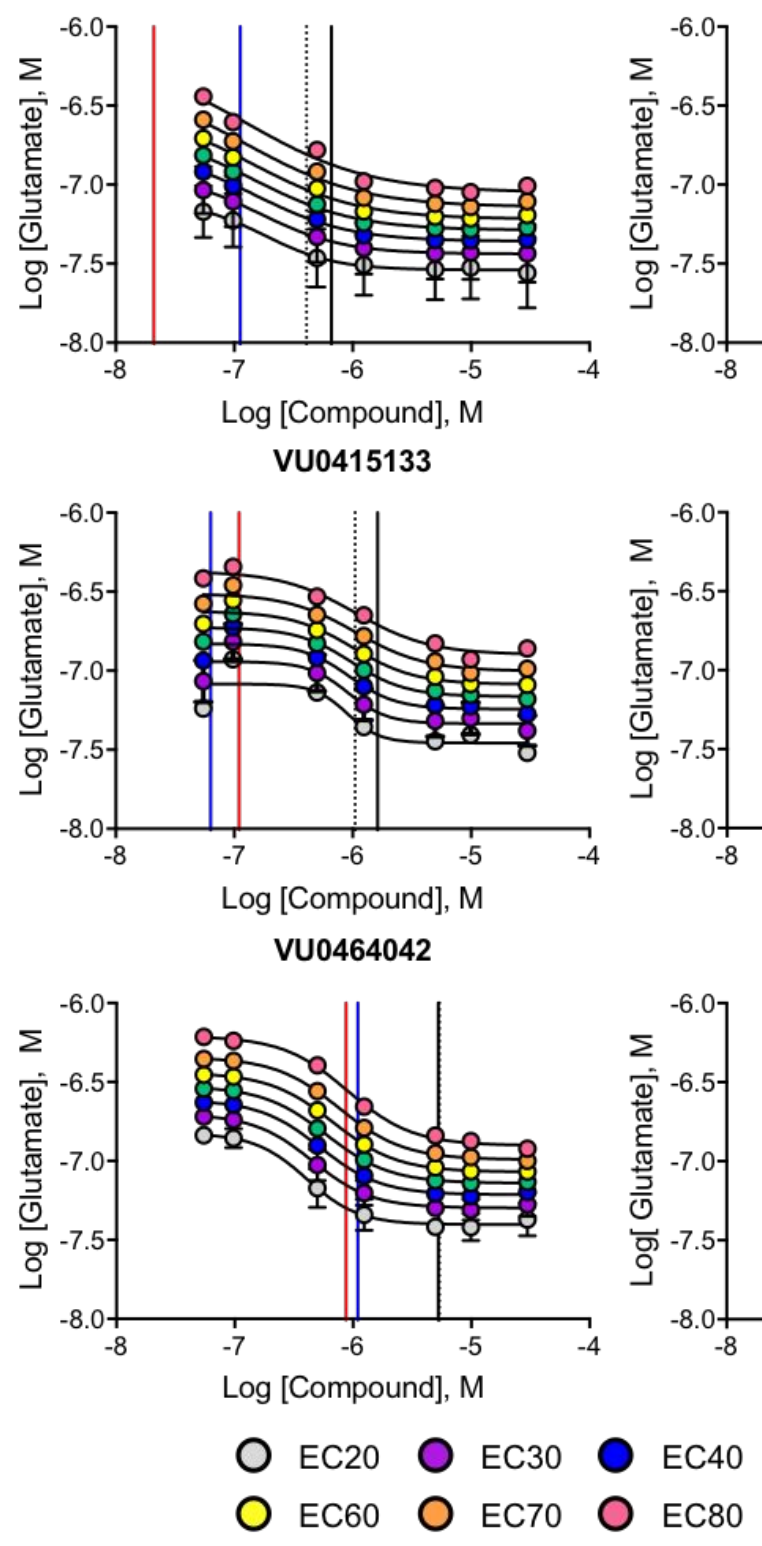

VU0464075
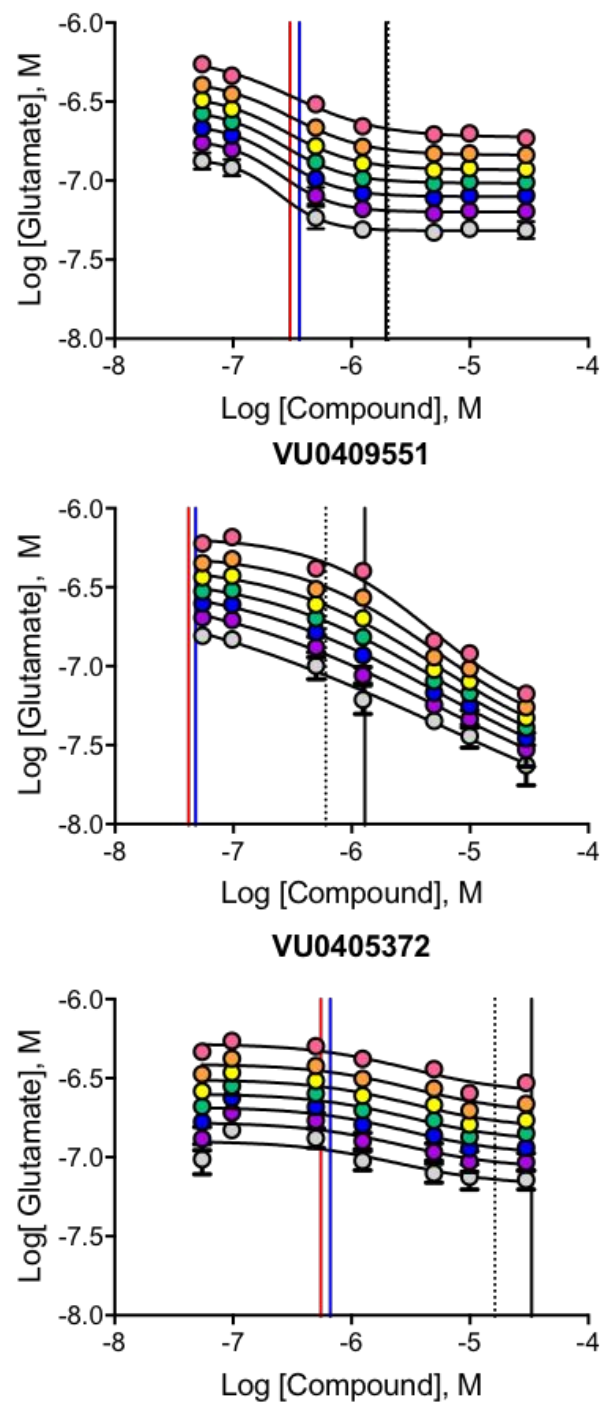

EC50 - Total brain
VU0447256
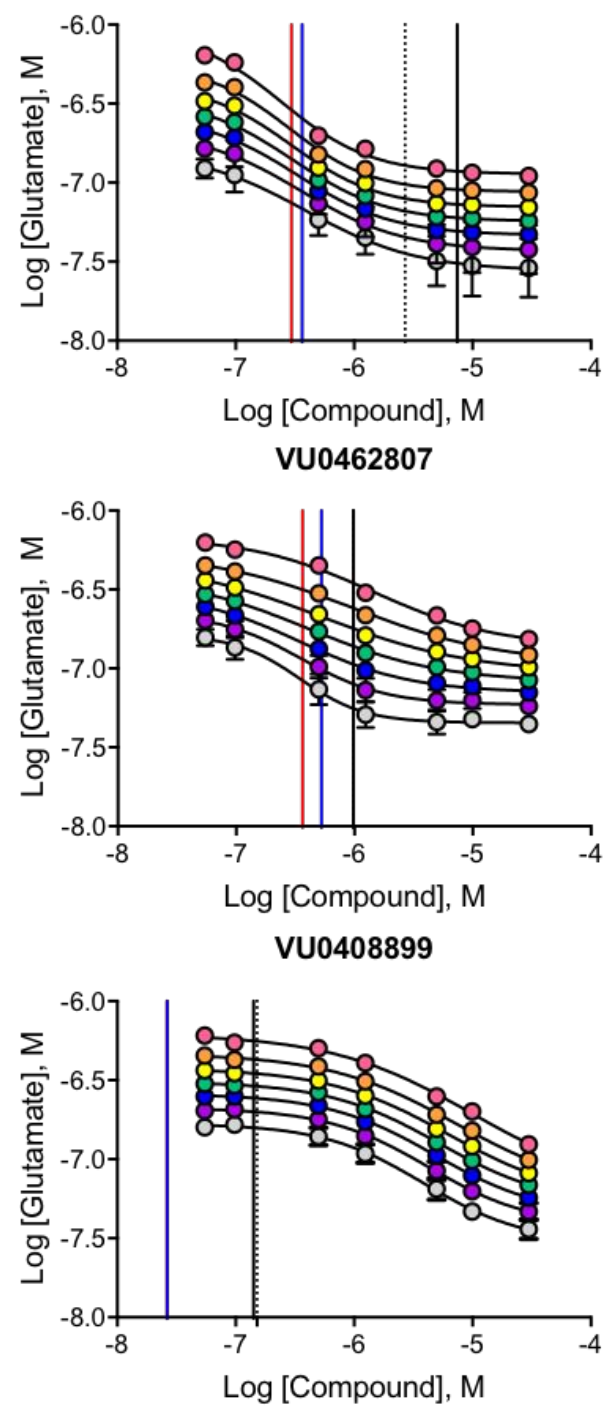

Supplemental Figure 7. Extrapolation of glutamate concentrations from combined in vitro and in vivo data. Data from in vitro full interaction studies with glutamate (Supplemental Figure 1) are transformed to plot the concentration of glutamate versus the concentration of PAM. The PAM concentrations needed to reverse AHL calculated for total brain, unbound brain, total plasma, and unbound plasma are shown by vertical lines and are listed numerically in Table 2 and Supplemental Tables 1-3. 
VU0455651

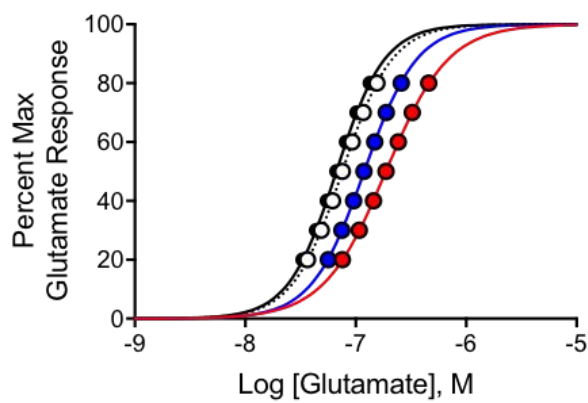

VU0415133

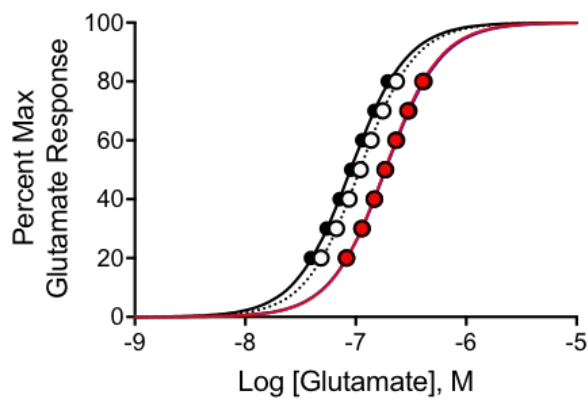

VU0464042

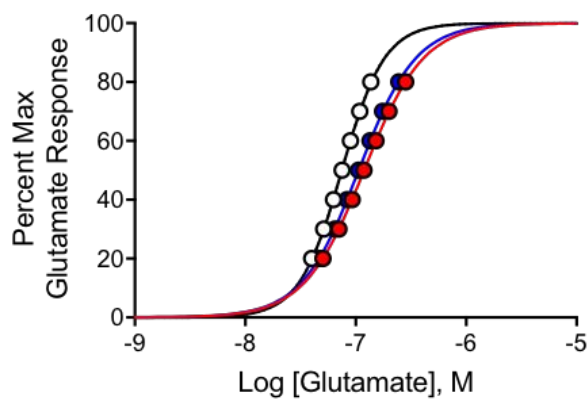

VU0464075

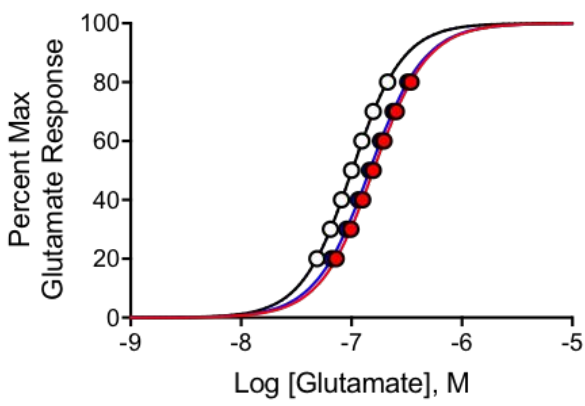

VU0409551

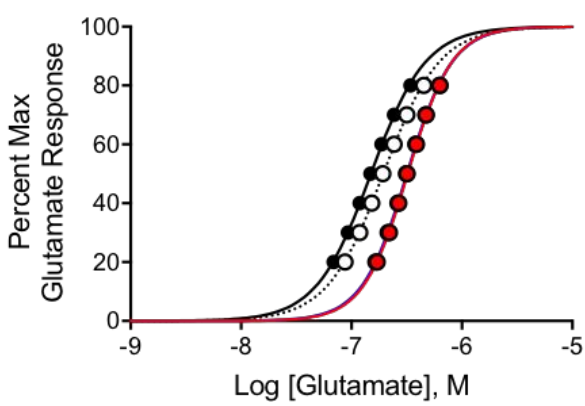

VU0405372

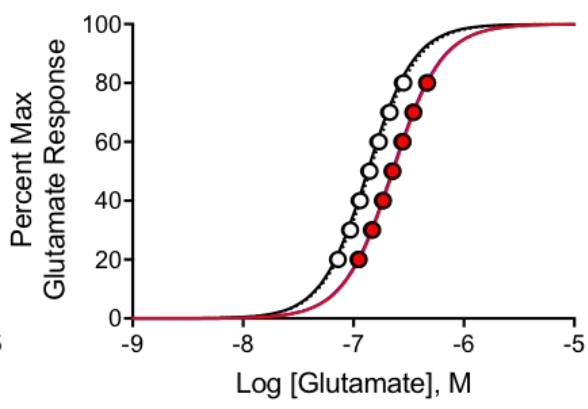

VU0447256

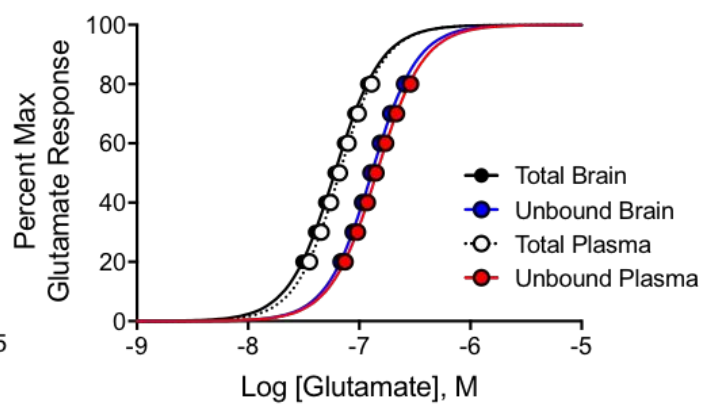

VU0462807

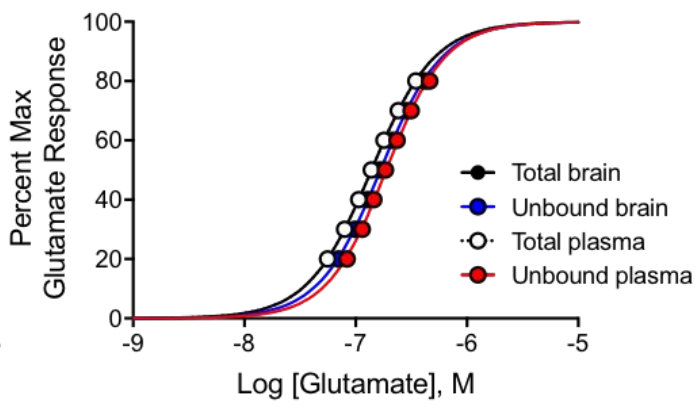

VU0408899

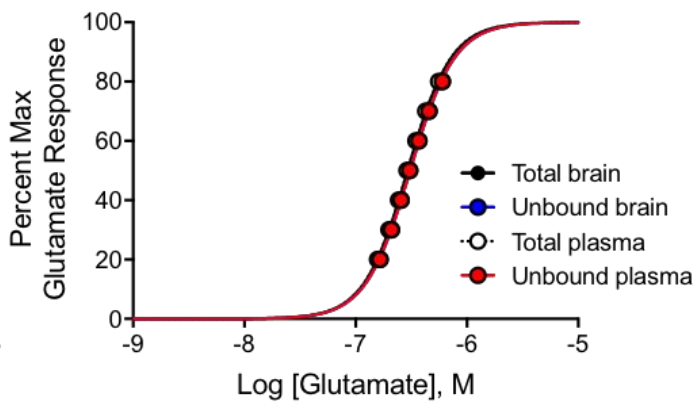

Supplemental Figure 8. Glutamate concentration-response curves generated at the PAM concentration that reverses AHL by $35 \%$ in vivo for each matrix. Curves for each matrix were generated from the data in Supplementary Figure 7. Derived $\mathrm{EC}_{50}$ values for these curves were averaged for all four matrices and are reported in Figure 5. 
Supplemental Table 1. Unbound Brain Curve Fits. These data are derived from the curve fits in Figure 3 and Supplemental Figure 3. Unbound brain concentrations were calculated by multiplying the percent predicted free fraction from brain homogenate binding experiments by the total brain concentration determined at each dose during AHL. Curves were fit with a three parameter logistical equation in GraphPad Prism using a bottom value of 0 ; when the top was unable to be fit, the top was constrained as noted below. The span was calculated as the distance between the bottom and top and divided by 2 to calculate $\%$ reversal at the determined $\mathrm{pEC}_{50}$ concentration. As can be noted by these values, each \% reversal value is unique. In the far right column, the unbound brain concentration $\left(\mathrm{C}_{\mathrm{Br}}\right.$ Unbound) at a constant $35 \%$ reversal was also calculated. Both the $\mathrm{EC}_{50}$ values as well as the $\mathrm{C}_{\mathrm{Br}}$ Unbound at $35 \%$ reversal values were used for correlation analysis.

\begin{tabular}{|c|c|c|c|c|}
\hline $\begin{array}{c}\text { Compound } \\
\text { ID }\end{array}$ & $\begin{array}{c}\mathrm{pEC}_{50} \\
\text { from AHL } \\
\text { curve fit } \\
\left(\mathrm{EC}_{50}, \mathrm{nM}\right)\end{array}$ & $\begin{array}{c}\mathrm{R}^{2} \text { of } \\
\text { Curve } \\
\text { Fit }\end{array}$ & $\left.\begin{array}{c}\text { Span/2 } \\
(\% \text { reversal } \\
\text { at EC }\end{array}\right)$ & $\begin{array}{c}\text { CBr Unbound at } \\
35 \% \text { reversal } \\
(\mathrm{nM})\end{array}$ \\
\hline VU0419832 & $\begin{array}{c}7.05 \pm 0.22 \\
(89)\end{array}$ & 0.573 & 50 & $\begin{array}{c}7.32 \\
(48)\end{array}$ \\
\hline VU0455651 & $\begin{array}{c}6.68 \pm 0.49 \\
(211)\end{array}$ & 0.466 & 50 & $\begin{array}{c}6.95 \\
(114)\end{array}$ \\
\hline VU0464075 & $\begin{array}{c}6.93 \pm 0.25 \\
(117)\end{array}$ & 0.501 & 23.1 & $\begin{array}{c}6.44 \\
(361)\end{array}$ \\
\hline VU0447256 & $\begin{array}{c}6.44 \pm 0.32 \\
(366)\end{array}$ & 0.462 & 35.1 & $\begin{array}{c}6.44 \\
(365)\end{array}$ \\
\hline VU0415133 & $\begin{array}{c}7.23 \pm 0.22 \\
(59)\end{array}$ & 0.653 & 33.5 & $\begin{array}{c}7.20 \\
(64)\end{array}$ \\
\hline VU0409551 & $\begin{array}{c}7.06 \pm 0.16 \\
(87)\end{array}$ & 0.705 & 49.1 & $\begin{array}{c}7.32 \\
(48)\end{array}$ \\
\hline VU0462807 & $\begin{array}{c}6.39 \pm 0.29 \\
(411)\end{array}$ & 0.442 & 32.3 & $\begin{array}{c}5.96 \\
(1099)\end{array}$ \\
\hline VU0464042 & $\begin{array}{c}5.79 \pm 0.21 \\
(1631)\end{array}$ & 0.595 & 43.4 & $\begin{array}{c}6.18 \\
(662)\end{array}$ \\
\hline VU0405372\# & $\begin{array}{c}6.70 \pm 0.50 \\
(198)\end{array}$ & 0.318 & 22.7 & $\begin{array}{c}7.58 \\
(26)\end{array}$ \\
\hline VU040889\# & $\begin{array}{c}7.55 \pm 0.26 \\
(28)\end{array}$ & 0.587 & 36.3 & \begin{tabular}{c}
528 \\
\hline
\end{tabular} \\
\hline
\end{tabular}

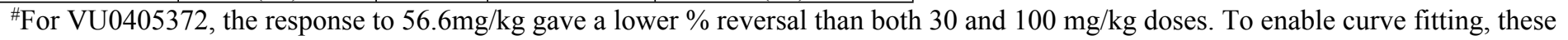
data were excluded from the fit.

a A constraint was used to define the top as between 0 and 100 , where $100 \%$ reversal was defined as the locomotor response for rats treated with vehicle/vehicle. Therefore Span/2 values equal to 50 represent curve fits were the top plateau was not completely defined by the doses used. 
Supplemental Table 2. Total Plasma Curve Fits. These data are derived from the curve fits in Figure 3 and Supplemental Figure 3. Total plasma values were determined at each dose during the AHL experiment and plotted versus the percent AHL reversal. Curves were fit with a three parameter logistical equation in GraphPad Prism using a bottom value of 0 ; when the tops of curves were unable to be fit, the top was constrained as noted below. The span was calculated as the distance between the bottom and top and divided by 2 to calculate $\%$ reversal at the determined $\mathrm{pEC}_{50}$ concentration. As can be noted by these values, each \% reversal value is unique when data are calculated in this way. In the far right column, the total plasma concentration $\left(\mathrm{C}_{\mathrm{Pl}}\right.$ Total) at a constant $35 \%$ reversal was also calculated. Both the $\mathrm{EC}_{50}$ values as well as the $\mathrm{C}_{\mathrm{Pl}}$ Total at $35 \%$ reversal values were used for correlation analysis.

\begin{tabular}{|c|c|c|c|c|}
\hline $\begin{array}{c}\text { Compound } \\
\text { ID }\end{array}$ & $\begin{array}{c}\mathrm{pEC} 50 \\
\text { from AHL } \\
\text { curve fit } \\
\left(\mathrm{EC}_{50}, \mu \mathrm{M}\right)\end{array}$ & $\begin{array}{c}\mathrm{R}^{2} \text { of } \\
\text { Curve Fit }\end{array}$ & $\left.\begin{array}{c}\text { Span/2 } \\
(\% \text { reversal } \\
\text { at EC }\end{array}\right)$ & $\begin{array}{c}\mathrm{C}_{\mathrm{Pl}} \text { total at } 35 \% \\
\text { reversal } \\
(\mu \mathrm{M})\end{array}$ \\
\hline VU0419832 & $\begin{array}{c}5.59 \pm 0.24 \\
(2.6)\end{array}$ & 0.559 & 50 & $\begin{array}{c}5.86 \\
(1.4)\end{array}$ \\
\hline VU0455651 & $\begin{array}{c}6.12 \pm 0.47 \\
(0.76)\end{array}$ & 0.484 & 50 & $\begin{array}{c}6.39 \\
(0.41)\end{array}$ \\
\hline VU0464075 & $\begin{array}{c}6.16 \pm 0.26 \\
(0.69)\end{array}$ & 0.503 & 23.4 & $\begin{array}{c}5.69 \\
(2.0)\end{array}$ \\
\hline VU0447256 & $\begin{array}{c}5.58 \pm 0.32 \\
(2.6)\end{array}$ & 0.459 & 34.4 & $\begin{array}{c}5.57 \\
(2.7)\end{array}$ \\
\hline VU0415133 & $\begin{array}{c}6.00 \pm 0.22 \\
(1.0)\end{array}$ & 0.649 & 34.0 & $\begin{array}{c}5.98 \\
(1.1)\end{array}$ \\
\hline VU0409551 & $\begin{array}{c}5.95 \pm 0.17 \\
(1.1)\end{array}$ & 0.703 & 50 & $\begin{array}{c}6.22 \\
(0.60)\end{array}$ \\
\hline VU0462807 & $\begin{array}{c}6.10 \pm 0.28 \\
(0.79)\end{array}$ & 0.445 & 31.6 & $\begin{array}{c}6.01 \\
(0.98)\end{array}$ \\
\hline VU0464042 & $\begin{array}{c}5.00 \pm 0.30 \\
(10)\end{array}$ & 0.586 & 50 & $\begin{array}{c}5.27 \\
(5.4)\end{array}$ \\
\hline VU0405372\# & $\begin{array}{c}5.30 \pm 0.53 \\
(5.0)\end{array}$ & 0.317 & 22.9 & $\begin{array}{c}4.79 \\
(16.1)\end{array}$ \\
\hline VU0408899 & $\begin{array}{c}6.80 \pm 0.25 \\
(0.16)\end{array}$ & 0.589 & 35.7 & $\begin{array}{c}6.82 \\
(0.15)\end{array}$ \\
\hline
\end{tabular}

"For VU0405372, the response to $56.6 \mathrm{mg} / \mathrm{kg}$ gave a lower $\%$ reversal than both 30 and $100 \mathrm{mg} / \mathrm{kg}$ doses. To enable curve fitting, these data were excluded from the fit.

a A constraint was used to define the top as between 0 and 100 , where $100 \%$ reversal was defined as the locomotor response for rats treated with vehicle/vehicle. Therefore Span/2 values equal to 50 represent curve fits were the top plateau was not completely defined by the doses used. 
Supplemental Table 3. Unbound Plasma Curve Fits. These data are derived from the curve fits in Figure 3 and Supplemental Figure 3. Unbound plasma concentrations were calculated by multiplying the percent predicted free fraction from plasma protein binding experiments by the total plasma concentration determined at each dose during AHL. Curves were fit with a three parameter logistical equation in GraphPad Prism using a bottom value of 0 ; when the tops of curves were unable to be fit, the top was constrained as noted below. The span was calculated as the distance between the bottom and top and divided by 2 to calculate \% reversal at the determined $\mathrm{pEC}_{50}$ concentration. As can be noted by these values, each \% reversal value is unique when data are calculated in this way. In the far right column, the unbound plasma concentration $\left(\mathrm{C}_{\mathrm{Pl}}\right.$ Unbound) at a constant $35 \%$ reversal was also calculated. Both the $\mathrm{EC}_{50}$ values as well as the $\mathrm{C}_{\mathrm{Pl}}$ Unbound at $35 \%$ reversal values were used for correlation analysis.

\begin{tabular}{|c|c|c|c|c|}
\hline Compound ID & $\begin{array}{c}\mathrm{pEC} \\
\text { from AHL } \\
\text { curve fit } \\
\left(\begin{array}{c}\mathrm{E} C_{50} \\
\mathrm{nM})\end{array}\right.\end{array}$ & $\begin{array}{c}\mathrm{R}^{2} \text { of } \\
\text { Curve Fit }\end{array}$ & $\begin{array}{c}\text { Span/2 } \\
(\% \text { reversal at } \\
\left.\mathrm{EC}_{50}\right)\end{array}$ & $\begin{array}{c}\mathrm{C}_{\mathrm{Pl}} \text { Unbound } \\
\text { at } 35 \% \\
\text { reversal } \\
(\mathrm{nM})\end{array}$ \\
\hline VU0419832 & $\begin{array}{c}6.68 \pm 0.24 \\
(211)\end{array}$ & 0.559 & 50 & $\begin{array}{c}6.95 \\
(114)\end{array}$ \\
\hline VU0455651 & $\begin{array}{c}7.41 \pm 0.46 \\
(39)\end{array}$ & 0.480 & 50 & $\begin{array}{c}7.68 \\
(21)\end{array}$ \\
\hline VU0464075 & $\begin{array}{c}6.99 \pm 0.26 \\
(104)\end{array}$ & 0.502 & 23.4 & $\begin{array}{c}6.52 \\
(305)\end{array}$ \\
\hline VU0447256 & $\begin{array}{c}6.55 \pm 0.32 \\
(283)\end{array}$ & 0.459 & 34.3 & $\begin{array}{c}6.53 \\
(295)\end{array}$ \\
\hline VU0415133 & $\begin{array}{c}6.99 \pm 0.22 \\
(103)\end{array}$ & 0.650 & 34.1 & $\begin{array}{c}6.96 \\
(109)\end{array}$ \\
\hline VU0409551 & $\begin{array}{c}7.11 \pm 0.16 \\
(78)\end{array}$ & 0.703 & 50 & $\begin{array}{c}7.38 \\
(42)\end{array}$ \\
\hline VU0462807 & $\begin{array}{c}6.53 \pm 0.28 \\
(295)\end{array}$ & 0.445 & 31.6 & $\begin{array}{c}6.44 \\
(366)\end{array}$ \\
\hline VU0464042 & $\begin{array}{c}5.79 \pm 0.30 \\
(1619)\end{array}$ & 0.586 & 50 & $\begin{array}{c}6.06 \\
(871)\end{array}$ \\
\hline VU0405372\# & $\begin{array}{c}6.77 \pm 0.53 \\
(168)\end{array}$ & 0.317 & 22.9 & $\begin{array}{c}6.26 \\
(546)\end{array}$ \\
\hline VU0408899 & $\begin{array}{c}7.56 \pm 0.25 \\
(28)\end{array}$ & 0.588 & 35.8 & $\begin{array}{c}7.58 \\
(26)\end{array}$ \\
\hline
\end{tabular}

"For VU0405372, the response to $56.6 \mathrm{mg} / \mathrm{kg}$ gave a lower $\%$ reversal than both 30 and $100 \mathrm{mg} / \mathrm{kg}$ doses. To enable curve fitting, these data were excluded from the fit.

${ }^{a}$ A constraint was used to define the top as between 0 and 100 , where $100 \%$ reversal was defined as the locomotor response for rats treated with vehicle/vehicle. Therefore Span/2 values equal to 50 represent curve fits were the top plateau was not completely defined by the doses used. 
Supplemental Table 4. Table of linear regression fits correlating in vivo $\mathrm{EC}_{50}$ concentration data with distinct in vitro pharmacological parameters calculated using operational modeling.

\begin{tabular}{|c|c|c|c|c|c|c|c|c|c|}
\hline & \multicolumn{3}{|c|}{$\begin{array}{c}\text { In vivo } \mathrm{pEC}_{50} \\
\text { vs In vitro } \mathrm{pEC} 50\end{array}$} & \multicolumn{2}{c|}{$\begin{array}{c}\text { In vivo } \\
\text { vE In vitro } \mathrm{p} K_{50}\end{array}$} & \multicolumn{2}{c|}{ In vivo $\mathrm{pEC}$ 50 vs In vitro Log $\alpha \beta$} \\
\hline & Slope & $\mathrm{R}^{2}$ & $\mathrm{p}$ & Slope & $\mathrm{R}^{2}$ & $\mathrm{p}$ & Slope & $\mathrm{R}^{2}$ & $\mathrm{p}$ \\
\hline Total Brain & $-0.323 \pm 0.358$ & 0.092 & 0.393 & $-0.161 \pm 0.358$ & 0.025 & 0.665 & $0.100 \pm 0.124$ & 0.075 & 0.445 \\
\hline Unbound Brain & $-0.414 \pm 0.400$ & 0.118 & 0.332 & $-0.427 \pm 0.383$ & 0.135 & 0.297 & $0.086 \pm 0.143$ & 0.043 & 0.568 \\
\hline Total Plasma & $-0.314 \pm 0.402$ & 0.071 & 0.610 & $-0.189 \pm 0.397$ & 0.027 & 0.647 & $0.090 \pm 0.140$ & 0.0496 & 0.536 \\
\hline Unbound Plasma & $-0.106 \pm 0.421$ & 0.008 & 0.808 & $-0.113 \pm 0.406$ & 0.009 & 0.788 & $0.093 \pm 0.141$ & 0.052 & 0.528 \\
\hline
\end{tabular}

\section{Supplemental References}

1. Rodriguez, A. L.; Grier, M. D.; Jones, C. K.; Herman, E. J.; Kane, A. S.; Smith, R. L.; Williams, R.; Zhou, Y.; Marlo, J. E.; Days, E. L.; Blatt, T. N.; Jadhav, S.; Menon, U. N.; Vinson, P. N.; Rook, J. M.; Stauffer, S. R.; Niswender, C. M.; Lindsley, C. W.; Weaver, C. D.; Conn, P. J., Discovery of novel allosteric modulators of metabotropic glutamate receptor subtype 5 reveals chemical and functional diversity and in vivo activity in rat behavioral models of anxiolytic and antipsychotic activity. Mol Pharmacol 2010, 78 (6), 1105-23.

2. Wood, M. R.; Noetzel, M. J.; Engers, J. L.; Bollinger, K. A.; Melancon, B. J.; Tarr, J. C.; Han, C.; West, M.; Gregro, A. R.; Lamsal, A.; Chang, S.; Ajmera, S.; Smith, E.; Chase, P.; Hodder, P. S.; Bubser, M.; Jones, C. K.; Hopkins, C. R.; Emmitte, K. A.; Niswender, C. M.; Wood, M. W.; Duggan, M. E.; Conn, P. J.; Bridges, T. M.; Lindsley, C. W., Discovery and optimization of a novel series of highly CNS penetrant M4 PAMs based on a 5,6-dimethyl-4-(piperidin-1yl)thieno[2,3-d]pyrimidine core. Bioorg Med Chem Lett 2016, 26 (13), 3029-3033.

3. Leach, K.; Sexton, P. M.; Christopoulos, A., Allosteric GPCR modulators: taking advantage of permissive receptor pharmacology. Trends Pharmacol Sci 2007, 28 (8), 382-9.

4. $\quad$ Mutel, V.; Ellis, G. J.; Adam, G.; Chaboz, S.; Nilly, A.; Messer, J.; Bleuel, Z.; Metzler, V.; Malherbe, P.; Schlaeger, E. J.; Roughley, B. S.; Faull, R. L.; Richards, J. G., Characterization of [(3)H]Quisqualate binding to recombinant rat metabotropic glutamate 1a and 5a receptors and to rat and human brain sections. J Neurochem 2000, 75 (6), 2590-601.

5. Gregory, K. J.; Noetzel, M. J.; Rook, J. M.; Vinson, P. N.; Stauffer, S. R.; Rodriguez, A. L.; Emmitte, K. A.; Zhou, Y.; Chun, A. C.; Felts, A. S.; Chauder, B. A.; Lindsley, C. W.; Niswender, C. M.; Conn, P. J., Investigating metabotropic glutamate receptor 5 allosteric modulator cooperativity, affinity, and agonism: enriching structure-function studies and structure-activity relationships. Mol Pharmacol 2012, 82 (5), 860-75. 